\title{
Familial Cancer Risk Shared Resource
}

National Cancer Institute

\section{Source}

National Cancer Institute. Familial Cancer Risk Shared Resource. NCI Thesaurus. Code C39400.

The Familial Cancer Risk Shared Resource provides Cancer Center investigators with clinical genetic expertise, data on familial genetic syndromes, germline mutations and cancer modifier genes; access to a database of genotyped probands with hereditary cancers; and clinical specimens with correlative epidemiologic data from subjects with genetically verified hereditary cancer. 